\title{
Chronic stress-induced immune dysregulation in breast cancer: Implications of psychosocial factors
}

\author{
Xiuyun Chen ${ }^{1}$, Mozhi Wang ${ }^{1}$, Keda Yu${ }^{2}$, Shouping $\mathrm{Xu}^{3}$, Pengfei Qiu ${ }^{4}$, Zhidong Lyu ${ }^{5}$, \\ Xinwen Zhang ${ }^{6}$, Yingying $\mathrm{Xu}^{1}$ \\ 'Department of Breast Surgery, the First Affiliated Hospital of China Medical University, Shenyang 110001, \\ Liaoning Province, China; \\ ${ }^{2}$ Department of Breast Surgery, Fudan University Shanghai Cancer Center, 270 Dong-An Road, Shanghai \\ 200032, China; \\ ${ }^{3}$ Department of Breast Surgery, Harbin Medical University Cancer Hospital, Harbin 150081, Heilongjiang \\ Province, China; \\ ${ }^{4}$ Breast Cancer Center, Shandong Cancer Hospital and Institute, Shandong First Medical University and \\ Shandong Academy of Medical Science, Jinan 250117, Shandong province, China; \\ ${ }^{5}$ Breast Center, The Affiliated Hospital of Qingdao University, Qingdao 266005, Shandong province, China; \\ ${ }^{6}$ Center of Implant Dentistry, School and Hospital of Stomatology, China Medical University, Liaoning Provincial \\ Key Laboratory of Oral Disease, Shenyang 110122, Liaoning Province, China
}

\section{ABSTRACT}

Chronic stress refers to continuous emotional changes and psychological pressure that individuals experience when they are unable to adjust and stabilize the internal environment over an extended period. It can increase the pressure on endocrine mediators and cytokines in the circulation, as well as tissues throughout the hypothalamic-pituitary-adrenaline (HPA) axis and sympathetic nervous system (SNS); thus, evolving the internal environment of the tumor. This review assesses several key issues, involving psychosocial factors, and integrates clinical, cellular, and molecular studies_as well as the latest research progress - to provide a mechanistic understanding regarding breast oncopsychology. We propose that chronic stress contributes to large individual differences in the prognosis of breast cancer survivors because they change the basic physiological processes of the endocrine and immune systems, which in turn regulate tumor growth. The study of psychological and physiological reactions of breast cancer patients suggests a new idea for psychological intervention and clinical treatment for breast cancer patients.

Key words: breast cancer, psychosocial, personality, immune function, prognosis

\section{INTRODUCTION}

The idea that breast cancer may be associated with chronic stress dates back to approximately $200 \mathrm{AD}$ when Galen pointed out that it is easier for depressed women to develop cancer than other women. ${ }^{[1,2]}$ Many reviews have been published in this field, some connecting psychosocial factors to the occurrence and development of the disease, and others focused on statistics without discussing corresponding mechanism. ${ }^{[3,4]}$ As cancer is a disease with biological diversity, no single psychosocial factor could be associated with all cancer development in the same way. ${ }^{[5-7]}$ This review combines the immune mechanism and clinical relevance of these pathways in breast cancer.

\section{NEUROENDOCRINE SYSTEM AND BREAST CANCER}

Stressful life events, including physical stressors and psychological stressors related to the social support and ability to cope with or habituate to repeated stress, are also determined by the way a person perceives and evaluates a situation. ${ }^{[8]}$ In contrast to acute stress, chronic stress refers to 
continuous emotional changes and psychological pressure that individuals experience when they are unable to adjust and stabilize the internal environment over an extended period. ${ }^{[3]}$

Over the past three decades, a psychophysiological mechanism has been believed to link psychosocial factors with breast cancer through the endocrine and immune systems. ${ }^{[9]}$ Increasingly more evidence has shown that moderate stress can impair the immune system, promoting cancer growth. ${ }^{[10]}$ The nervous system receives a variety of stimuli in vivo and in vitro. It converts the stimulation into nerve impulses for conduction, thereby regulating the physiological activities of organs-including endocrine glands-and transforming appropriate responses. ${ }^{[1]}$ Cognitive responses from the cerebral cortex and limbic systems regulate the activities of hypothalamic and brainstem structures, which directly control the activities of the hypothalamic-pituitary-adrenaline (HPA) axis and sympathetic nervous system (SNS). ${ }^{[12-14]}$

\section{Hypothalamic-pituitary-adrenergic axis}

The HPA axis is the critical system active in stress response. The paraventricular nucleus of the hypothalamus is excited by various internal and external stimuli. Corticotropinreleasing hormone $(\mathrm{CRH})$ is synthesized and then secreted into the pituitary gland to produce adreno-cortico-tropic hormone (ACTH). ACTH circulates to the adrenal cortex and releases glucocorticoids, which are involved in almost every organ system. ${ }^{[15]}$ Glucocorticoids can also directly or indirectly affect the growth of tumors by participating in the basic biological processes of metabolism, immune function, angiogenesis, circadian rhythm, and neuron function.

The combination of glucocorticoids and glucocorticoid receptors can stimulate the expression of antiapoptotic gene in epithelial cells and antagonize the apoptosis induced by anticancer drugs. ${ }^{[16]}$ Glucocorticoids promote the proliferation and survival of tumor cells. ${ }^{[17,18]}$ Both chronic stress and exogenous glucocorticoid supplementation can lead to drug resistance to paclitaxel and lead to larger tumors. ${ }^{[19]}$ Similarly, in the culture of triple negative breast cancer cells with positive glucocorticoid receptors, the use of glucocorticoid receptor antagonists can improve the efficacy of paclitaxel-induced cytotoxicity and apoptosis. ${ }^{[20,21]}$

\section{Sympathetic nervous system}

When sympathetic nerves are excited, secretions from the adrenal medulla increase. Norepinephrine and epinephrine are released into the blood from sympathetic postganglionic fibers and the adrenal medulla. NE binds to adrenergic receptors to regulate tumor growth, progression, and metastasis. ${ }^{[22-24]} \beta$-Adrenergic signaling may affect the development of breast cancer through several direct and indirect mechanisms, including tumor cell invasion, angiogenesis, tumor cell survival, and tumor immune interaction. ${ }^{[25]}$ A variety of tumors increase vascular endothelial growth factor, matrix metalloproteinase-2, and hypoxia inducible factor- $1 \alpha$ through the cAMP protein kinase signaling pathway activated by $\beta$-adrenergic receptor, which promotes tumor angiogenesis. ${ }^{[2]}$ Chronic stress also increases the expression of proinflammatory cytokines IL-6 and IL-8. ${ }^{[27,28]}$ In animal experiments, we found that stress-induced neuroendocrine activation had little effect on the growth of primary breast cancer, but the metastasis of distant tissues increased 30-fold. ${ }^{[2]]}$

Chronic stress reconstituted lymphatic network plays an important role in tumor interior and surrounding, providing a pathway for tumor cell escape. ${ }^{[30,31]}$ Drug inhibition of sympathetic nervous system blocks the effect of chronic stress on lymphatic remodeling in vivo and reduces lymph node metastasis in preclinical cancer models and breast cancer patients. This may be a new way of how activating the sympathetic nervous system can stimulate cancer outcomes. ${ }^{[3]}$

\section{PSYCHONEUROIMMUNOLOGY AND BREAST CANCER}

Psychoneuroimmunology refers to the mutual communication between the brain and the immune system under equal conditions, emphasizing that psychological and neural phenomena can affect the immune system. It studies how neuralgia transforms psychological factors into chronic stress that can affect healthy behavior, especially how the brain and behavior affect immune system and, in turn, are controlled by the immune system. ${ }^{[33]}$ The nervous system acts on the neuroendocrine system through a wide range of peripheral synapses, neurotransmitters, endocrine hormones, and cytokines secreted by nerve cells. These neurotransmitters affect immune function and their receptors act on immune cells like lymphocytes and macrophages. ${ }^{[34]}$ Neuroendocrine system and immune system share the same signal media and receptors, which indicates that the brain has immune regulation function and immune system has a sensory function. ${ }^{[35]}$ It is known that the nervous system regulates the immune system mainly through HPA and SNS (Figure 1). At present, steroid hormone receptors, catecholamine receptors, opioid receptors, peptide receptors, and other receptors regulated by neuroendocrine regulation have been found in organs and cells of the immune system. Chronic stress changes the quantity and rhythm of hormone secretion and acts on the endocrine system, most of which are immunosuppressive. ${ }^{[36-38]}$

Glucocorticoid is known as an immunosuppressant, which regulates the release, synthesis, and function of cytokines as well as inhibits other substances regulating immunity 


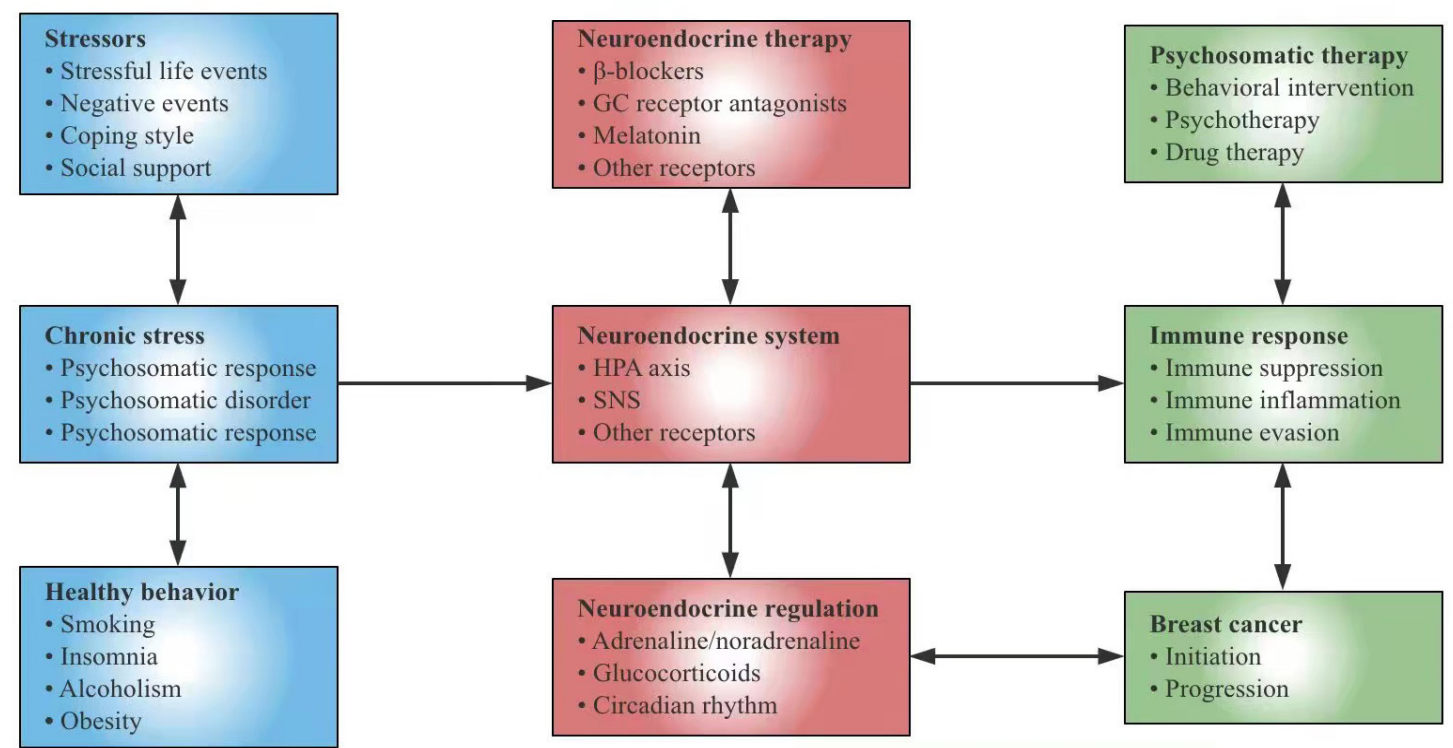

Figure 1: Chronic stress affects the pathogenesis of breast cancer through neuroendocrine pathways. In this model, psychosocial factors and healthy behavior regulate adrenaline, noradrenocortin, and glucocorticoid through the neuroendocrine system. Stress-responsive neuroendocrine mediators can also affect the immune system and control cell proliferation, invasion, angiogenesis, metastasis, and immune escape. In addition to explaining the biological behavioral risk factors of breast cancer, the model also proposes new targets for behavioral intervention, psychological intervention, and drug therapy. HPA: hypothalamicpituitary-adrenaline; SNS: sympathetic nervous system; GC: glucocorticoid.

and inflammation. At the same time, the circadian rhythm of cortisol is also closely related to the occurrence and development of breast cancer. ${ }^{[39,40]}$ Studies have shown that the diurnal rhythm of cortisol in patients with metastatic breast cancer is usually flattened or abnormal which inhibits NK cell count and NK function, resulting in early mortality. ${ }^{[4]}$ Thus, we speculate that NK cells may be mediators or markers of the rapid disease progression in breast cancer.

Stimulation of $\beta$-adrenergic receptors usually inhibits lymphocyte response, cytotoxicity of NK cells, and antigen extraction function of dendritic cells, and promotes tumor cell metastasis. Studies have shown that pressure activated neuroendocrine system and increased NE secretion can promote the infiltration and differentiation of $\mathrm{CD} 11 \mathrm{~b}+\mathrm{F} 4 / 80+$ cells into $\mathrm{M} 2$ macrophages, promoting the metastasis of breast cancer cells to lymph nodes and lung while not affecting the growth of primary tumor. ${ }^{[42]}$

\section{THE INFLUENCE OF PSYCHOLOGICAL FACTORS OF BREAST CANCER PATIENTS ON TUMOR}

Stressful life events, including physical stressors and psychological stressors related to the social support and ability to cope with or habituate to repeated stress, are also determined by the way a person perceives and evaluates a situation. ${ }^{[43]}$

\section{Stressful life events}

Adverse life events include stressful life events, death of spouse, death of relatives or friends, personal health problems, divorce, income changes, and environmental changes. Many epidemiological studies have been done on whether adverse life events promote the occurrence of breast cancer. For example, because of changes in spousal relationships like divorce or death of a spouse, the risk of breast cancer after a broken marriage significantly triples. ${ }^{[4]}$ The study found that extreme pressure, along with low social support, was associated with a great increase in the incidence rate of breast cancer. ${ }^{[45]}$ However, some of the meta-analysis showed that there was no correlation between the two. ${ }^{[46]}$ Additionally, important interactions between behavioral stress factors and healthy behaviors, such as smoking, insomnia, alcoholism, and obesity, would further influence cancer risk. ${ }^{[12,47]}$ The difference in everyone's life experience, personality, and cognitive evaluation of life events affects the accuracy of stress assessment; therefore, it is impossible to find a clear answer from the epidemiology. However, laboratory molecular research can make up for this defect. ${ }^{[48]}$ The central nervous system and the limbic system of the brain become excessively tense under chronic mental stress. ${ }^{[4]}$ The thymus degenerates through steroid action, which not only weakens the immune function but also easily causes gene program error to manifest. 
This increases the sensitivity of carcinogenic factors. ${ }^{[00-52]}$ Studies have shown that in the face of negative life events for regional breast cancer after surgical treatment, stress levels significantly reduced NK cell lysis, NK cell response to recombinant interferon gamma (IFN- $\gamma$ ), and peripheral blood lymphocyte proliferation response to phytoagglutinin and monoclonal antibodies against T-cell receptors. Other work in this field has established a link between psychosocial factors and lymphocyte proliferation in breast cancer patients. ${ }^{[53]}$

\section{Emotional expression}

Current researches have shown that mental illness is likely to increase the risk of death in patients with breast cancer. Depression is one of the most common mental diseases in breast cancer. A large population-based study in South Korea has found that breast cancer patients with depression and anxiety have the highest risk of death, followed by patients with depression and anxiety alone. ${ }^{[54}$ The link between mental health problems and increased mortality is consistent with previous findings on breast cancer patients in an analysis of Danish population-based health registration data. ${ }^{[5]}$ Similarly, in another study, depression had a predicted all-cause mortality rather than breast cancer-specific mortality. ${ }^{[56]}$ Negative emotions may interfere with the compliance of health promotion behavior, affect the quality of life and the doctor-patient relationship, and increase the burden of physical symptoms of cancer patients.

Depression is also associated with a poor cellular immune response to specific antigens in patients with breast cancer. The relationship among depressive symptoms, cortisol secretion, and cellular immune response in 72 patients with metastatic breast cancer was investigated. Cellmediated immunity of specific antigens was determined after intradermal administration of seven common antigens. Women with depressive symptoms showed immunosuppressive effects, such as mean induration size, while those with higher mean cortisol levels responded less to antigens. ${ }^{[57]}$ Previous clinical studies have shown that higher levels of cancer-specific anxiety were associated with lower NK cytotoxicity in breast cancer patients. ${ }^{[58]}$ In general, excessive anxiety and depression can cause the decline of immune function, reduce the activity of NK cells in the body, reduce the level of antibodies secreted by cells, and increase the chance of recurrence and metastasis of breast cancer.

\section{Coping style}

For a long time, it has been speculated that personality traits are related to breast cancer, but study results are often inconsistent. Data from cancer patients show that those who tend to be pessimistic and negative in the face of the huge pain caused by the diagnosis and treatment of cancer may experience accelerated disease development. ${ }^{[59]}$
On the contrary, positive psychosocial factors, such as social support and optimism, predict longer survival. ${ }^{[60]}$ Coping plays an important regulatory role between stressors and stress response. Coping style mainly includes the assessment and regulation of stress and the physical or emotional response related to the event. Personality and coping style are related to a number of peripheral blood immune cells and cellular immune function. The escape coping mechanism of a breast cancer diagnosis is related to interrupted circadian rhythm, which affects the survival rate of breast cancer patients. ${ }^{[61]}$ For example, pain and avoidance coping are associated with interruptions to the circadian rhythm, which in turn is associated with a flattening of the daily cortisol rhythm curve in breast cancer patients before surgery. Some studies tested the coping methods and attitudes of breast cancer patients by MAC questionnaire on the day before surgery while concurrently detecting the number of lymphocytes and their subsets. It was found that negative coping styles negatively correlated with the total number of lymphocytes, B lymphocytes, $\mathrm{CD} 3$, and $\mathrm{CD}^{4} .^{\left[{ }^{[2]}\right.}$ In metastatic breast cancer, we found that spiritual expression was associated with an increase in the number of white blood cells and circulating T cells, including Th cells and cytotoxic T cells. ${ }^{[63]}$ Increased NK cell activity was found in cancer patients who used humor as a coping mechanism. ${ }^{[64]}$

\section{Social support}

Studies have examined the impact of social support on the survival of breast cancer patients. Compared with the social integration cohort, women diagnosed with breast cancer who experienced social isolation had a $66 \%$ increased risk of all-cause death and a three-fold increase in breast cancer-related mortality ${ }^{[6]} \mathrm{A}$ similar study, which followed young women subsequent to breast cancer diagnosis, found that larger social network correlated with lower all-cause mortality rather than breast cancer-specific mortality. However, this study focused on the number of social relationships. The quality of intimacy was found to be closely related to mortality in breast cancer patients. ${ }^{[6]}$ For example, when social networks are small, women with low social support have an increased risk of breast cancerrelated death compared to women with high social support.

Social support can be perceived and translated into processes that alter the cellular chemistry of breast cancer. ${ }^{[67]}$ Social isolation can increase the risk for occurrence of and death from diseases. A large amount of evidence shows that social support may have survival value in animal and human groups. Genome-wide expression analysis in adults with increased loneliness showed upregulated expression of proinflammatory transcripts related to nuclear factor kappa B activation and downregulated expression of antiinflammatory gene expression related 
to glucocorticoid receptor activation. ${ }^{[12]}$ Additionally, the sensitivity of glucocorticoid receptor will be negatively affected, leading to a decrease in the antiinflammatory effect of glucocorticoids. ${ }^{[68]}$ There is a close relationship between social support and immune function. Perceived social support is conducive to increased NK activity. ${ }^{[09]}$

\section{CLINICAL OPPORTUNITIES AND CHALLENGES}

The comprehension of psychosocial factors on the biological and clinical significance of cancer is extending. Although the molecular pathways have not been fully described, observations to date recommend the need for new therapeutic paradigms that integrate biological behavior perspectives.

Positive psychosocial factors, such as social support, have been associated with increased cytotoxic levels of NK cells in breast cancer. With the support of society, the cytotoxicity of NK cells is not limited to the surrounding areas; it is also found in tumor-infiltrating lymphocytes, reflecting the possible psychosocial impact on the tumor microenvironment. ${ }^{[70]}$ Stress management interventions that inhibit chronic stress-related physiological changes may contribute to the recovery of the immune system, thereby increasing immune monitoring during active cancer treatment. ${ }^{[71]}$ For example, in patients with breast cancer, cognitive-behavioral stress management (CBSM) and mindfulness-based stress reduction (MBSR) can reverse the anxiety-related upregulation of circulating leukocyte proinflammatory gene expression. ${ }^{[53,72,73]}$

Similar to most medical interventions for cancer, the effectiveness of psychosocial interventions may vary with the type and stage of cancer, patient characteristics, and the type and extent of health behavior interventions. More importantly, epidemiological evidence related to psychological and social factors provides evidence for studying the biological signaling pathways and mechanisms underlying these observations. A drug intervention can be used to improve stress-related effects on cancer development and progression.

Drugs that can reestablish circadian regulation, such as melatonin, may have antitumor effects. ${ }^{[74]}$ In a retrospective study of patients with breast cancer, there demonstrated a $57 \%$ reduced risk of metastasis development and a $71 \%$ reduction in the risk of breast cancer-specific mortality after 10 years after adjusting for tumor size, stage, and grade in women taking any $\beta$-blocker compared to those who were not. ${ }^{[24]}$ The use of antidepressants may be promising, as it has been associated with certain types of cancer, along with inhibition of inflammatory response. ${ }^{[7]}$
Whether these agents can be used to reduce cancer risk through mechanisms related to biological behavior remains to be determined, but these studies suggest that further investigation is needed. ${ }^{[76,77]}$ However, previous studies on the use of antidepressants in breast cancer have shown that there is an association between antidepressants and the risk of death is a complex issue that should be considered, such as the type of antidepressants and cancer treatment patients are receiving. ${ }^{[78]}$

\section{DISCUSSION}

Psychosocial stress can damage the immune system through neuroendocrine inhibition, leading to the growth of malignant tumors and affecting their course and outcome. The role and mechanism of chronic stress in the development of breast cancer need a model, which recognizes the relationship between the neuroendocrine and immune systems. However, the biological factors that link chronic stress with breast cancer prognosis still need to be found and verified. ${ }^{[79,80]}$ At the theoretical level, considering the unusual complexity of these intermediary markers and systems, it may be necessary to test and model their relationships in a hierarchical model. ${ }^{[81]}$ Future studies should examine the effect of these biomarkers on the prognosis of breast cancer patients along with their related psychosocial factors and stress. ${ }^{[22,83]}$

At the same time, we should not only explore the biological significance of mediators but also their clinical significance for patient health. However, chronic stress has various forms, different severity, and duration, which are difficult to control. Large-scale and well-designed studies on chronic stress related to breast cancer development are needed. Prospective studies are ideal and need to be designed with sufficient sample sizes. Multiple psychosocial factors can be examined simultaneously with objective assessments, focusing on their quality rather than cumulative effects. The impact of psychosocial factors on cancer progression has been shown to be more convincing than the onset of cancer; however, the possible cause of the expected relationship has not been identified. Although evidence is lacking regarding the main role of psychosocial factors in breast cancer development, the interactions between several psychological factors-as well as the interaction between psychological and biomedical risk factors-have rarely been studied.

Previous reports have shown that a large proportion of cancer patients with comorbidities do not receive treatment. ${ }^{[84]}$ It is necessary to improve the reception and recovery of mental health assessment and treatment. However, the results of psychiatric interventions that enhance effective coping and reduce affective distress seem to have 
beneficial effects on breast cancer survival but are not proposed as an alternative or independent treatment. ${ }^{[85]}$ As cancer treatment evolves toward a more patient-specific approach, we can make best of psychological factors and psychotherapy to prevent the occurrence and development of cancer as well as improve the immune status of breast cancer patients through molecular biology, so as to prolong life and improve the quality of life.

\section{Conflict of Interest}

The authors have no conflicts of interest to disclose.

\section{Source of Funding}

This work was supported by the National Natural Science Foundation of China (81773083), the Chinese Young Breast Experts Research project (CYBER-2021-A02), the Scientific and Technological Innovation Leading Talent Project of Liaoning Province (XLYC1802108), and the Support Project for Young and Technological Innovation Talents of Shenyang (RC190393).

\section{Authors' Contributions}

Chen XY and Wang MZ wrote the manuscript. Yu KD and $\mathrm{Xu}$ SP contributed to the conception of the article and review of literature. Qiu PF and Lyu ZD contributed to manuscript editing and manuscript review. Xu YY designed the study and takes the responsibility for the integrity of the work as a whole from inception to the published article. All of the authors critically revised this work and approved the version.

\section{REFERENCES}

1. Stiefel F, Guex P. Cancer and the mind--do we still believe Galen? Eur J Cancer 1996;32A:2041.

2. Elefteriou F. Chronic stress, sympathetic activation and skeletal metastasis of breast cancer cells. Bonekey Rep 2015;4:693.

3. Russell G, Lightman S. The human stress response. Nat Rev Endocrinol 2019;15:525-34.

4. Krizanova O, Babula P, Pacak K. Stress, catecholaminergic system and cancer. Stress 2016;19:419-28.

5. Zhang Z, Wang Y, Li Q. Mechanisms underlying the effects of stress on tumorigenesis and metastasis (Review). Int J Oncol 2018;53:2332-42.

6. Cohen L, Cole SW, Sood AK, Prinsloo S, Kirschbaum C, Arevalo JMG, et al. Depressive symptoms and cortisol rhythmicity predict survival in patients with renal cell carcinoma: role of inflammatory signaling. PLoS One 2012;7:e42324.

7. Shan T, Ma J, Ma Q, Guo K, Guo J, Li X, et al. $\beta 2$-AR-HIF-1 $\alpha$ : a novel regulatory axis for stress-induced pancreatic tumor growth and angiogenesis. Curr Mol Med 2013;13:1023-34.

8. Warner ET, Park ER, Luberto CM, Rabin J, Perez GK, Ostroff JS. Internalized stigma among cancer patients enrolled in a smoking cessation trial: The role of cancer type and associations with psychological distress. Psycho-Oncology 2021; November 19. [Online ahead of print].

9. Morris LS. Toward Equity: Understanding the Impact of Environmental
Stressors on Neural-Immune Interactions During Childhood Development. Bio Psychiatry 2021;90:138-40.

10. Stefanaki C, Pervanidou P, Boschiero D, Chrousos GP. Chronic stress and body composition disorders: implications for health and disease. Hormones (Athens) 2018;17:33-43.

11. Ruiz NAL, Del Ángel DS, Brizuela NO, Peraza AV, Olguín HJ, Soto MP, et al. Inflammatory Process and Immune System in Major Depressive Disorder. Int J Neuropsychopharmacol 2022;25:46-53.

12. Yang H, Xia L, Chen J, Zhang S, Martin V, Li Q, et al. Stressglucocorticoid-TSC22D3 axis compromises therapy-induced antitumor immunity. Nat Med 2019;25:1428-41.

13. Sapolsky RM, Romero LM, Munck AU. How do glucocorticoids influence stress responses? Integrating permissive, suppressive, stimulatory, and preparative actions. Endocrine Rev 2000;21:55-89.

14. Glaser R, Kiecolt-Glaser JK. Stress-induced immune dysfunction: implications for health. Nat Rev Immunol 2005;5:243-51.

15. Westfall S, Iqbal U, Sebastian M, Pasinetti GM. Gut microbiota mediated allostasis prevents stress-induced neuroinflammatory risk factors of Alzheimer's disease. Prog Mol Biol Transl Sci 2019;168:147-81.

16. Feng Z, Liu L, Zhang C, Zheng T, Wang J, Lin M, et al. Chronic restraint stress attenuates p53 function and promotes tumorigenesis. Proc Natl Acad Sci U S A 2012;109:7013-8.

17. Moran TJ, Gray S, Mikosz CA, Conzen SD. The glucocorticoid receptor mediates a survival signal in human mammary epithelial cells. Cancer Res 2000;60:867-72.

18. Wu W, Chaudhuri S, Brickley DR, Pang D, Karrison T, Conzen SD. Microarray analysis reveals glucocorticoid-regulated survival genes that are associated with inhibition of apoptosis in breast epithelial cells. Cancer Res 2004;64:1757-64.

19. Pang D, Kocherginsky M, Krausz T, Kim S-Y, Conzen SD. Dexamethasone decreases xenograft response to Paclitaxel through inhibition of tumor cell apoptosis. Cancer Biol Ther 2006;5:933-40.

20. Reeder A, Attar M, Nazario L, Bathula C, Zhang A, Hochbaum D, et al. Stress hormones reduce the efficacy of paclitaxel in triple negative breast cancer through induction of DNA damage. Br J Cancer 2015;112:1461-70.

21. Reeder A, Attar M, Nazario L, Bathula C, Zhang A, Hochbaum D, et al. Stress hormones reduce the efficacy of paclitaxel in triple negative breast cancer through induction of DNA damage. Br J Cancer 2015;112:1461-70.

22. Neeman E, Zmora O, Ben-Eliyahu S. A new approach to reducing postsurgical cancer recurrence: perioperative targeting of catecholamines and prostaglandins. Clin Can Res 2012;18:4895-902.

23. Ayroldi E, Cannarile L, Adorisio S, Delfino DV, Riccardi C. Role of Endogenous Glucocorticoids in Cancer in the Elderly. Int J Mol Sci 2018;19.

24. Hiller JG, Cole SW, Crone EM, Byrne DJ, Shackleford DM, Pang J-MB, et al. Preoperative $\beta$-Blockade with Propranolol Reduces Biomarkers of Metastasis in Breast Cancer: A Phase II Randomized Trial. Clin Can Res 2020;26:1803-11.

25. Walker AK, Martelli D, Ziegler AI, Lambert GW, Phillips SE, Hill SJ, et al. Circulating epinephrine is not required for chronic stress to enhance metastasis. Psychoneuroendocrinology. 2019;99:191-5.

26. Liu J, Deng GH, Zhang J, Wang Y, Xia XY, Luo XM, et al. The effect of chronic stress on anti-angiogenesis of sunitinib in colorectal cancer models. Psychoneuroendocrinology 2015;52:130-42.

27. Chen H, Liu D, Guo L, Cheng X, Guo N, Shi M. Chronic psychological stress promotes lung metastatic colonization of circulating breast cancer cells by decorating a pre-metastatic niche through activating $\beta$-adrenergic signaling. J Pathol 2018;244:49-60.

28. Le Bras A. Chronic stress and inflammation. Lab Anim (NY) 2021;50:309.

29. Shaashua L, Shabat-Simon M, Haldar R, Matzner P, Zmora O, Shabtai $\mathrm{M}$, et al. Perioperative COX-2 and $\beta$-Adrenergic Blockade Improves Metastatic Biomarkers in Breast Cancer Patients in a Phase-II Randomized Trial. Clin Can Res 2017;23:4651-61.

30. Stacker SA, Williams SP, Karnezis T, Shayan R, Fox SB, Achen MG. 
Lymphangiogenesis and lymphatic vessel remodelling in cancer. Nat Rev Cancer 2014;14:159-72.

31. Le CP, Nowell CJ, Kim-Fuchs C, Botteri E, Hiller JG, Ismail H, et al. Chronic stress in mice remodels lymph vasculature to promote tumour cell dissemination. Nat Commun 2016;7:10634.

32. Barbieri A, Palma G, Rosati A, Giudice A, Falco A, Petrillo A, et al. Role of endothelial nitric oxide synthase (eNOS) in chronic stress-promoted tumour growth. J Cell Mol Med 2012;16:920-6.

33. Hadamitzky M, Lückemann L, Pacheco-López G, Schedlowski M. Pavlovian Conditioning of Immunological and Neuroendocrine Functions. Physiol Rev 2020;100:357-405.

34. de Abreu MS, Giacomini ACVV, Zanandrea R, Dos Santos BE, Genario R, de Oliveira GG, et al. Psychoneuroimmunology and immunopsychiatry of zebrafish. Psychoneuroendocrinology 2018;92.

35. Roubalová R, Procházková P, Papežová H, Smitka K, Bilej M, TlaskalováHogenová H. Anorexia nervosa: Gut microbiota-immune-brain interactions. Clin Nutr 2020;39:676-84.

36. Wieduwild E, Girard-Madoux MJ, Quatrini L, Laprie C, Chasson L, Rossignol R, et al. $\beta 2$-adrenergic signals downregulate the innate immune response and reduce host resistance to viral infection. J Exp Med 2020;217.

37. Hu D, Wan L, Chen M, Caudle Y, LeSage G, Li Q, et al. Essential role of IL-10/STAT3 in chronic stress-induced immune suppression. Brain Behav Immun 2014;36:118-27.

38. Matzner P, Sandbank E, Neeman E, Zmora O, Gottumukkala V, BenEliyahu S. Harnessing cancer immunotherapy during the unexploited immediate perioperative period. Nat Rev Clin Oncol 2020;17:313-26.

39. Sloan EK, Priceman SJ, Cox BF, Yu S, Pimentel MA, Tangkanangnukul $\mathrm{V}$, et al. The sympathetic nervous system induces a metastatic switch in primary breast cancer. Cancer Res 2010;70:7042-52.

40. Sulli G, Lam MTY, Panda S. Interplay between Circadian Clock and Cancer: New Frontiers for Cancer Treatment. Trends Cancer 2019;5:47594.

41. Sephton SE, Lush E, Dedert EA, Floyd AR, Rebholz WN, Dhabhar FS, et al. Diurnal cortisol rhythm as a predictor of lung cancer survival. Brain Behav Immun 2013;30 Suppl:S163-70.

42. Antoni MH, Dhabhar FS. The impact of psychosocial stress and stress management on immune responses in patients with cancer. Cancer 2019;125:1417-31.

43. Weckesser LJ, Schmidt K, Möschl M, Kirschbaum C, Enge S, Miller R. Temporal stability and effect dynamics between executive functions, perceived chronic stress, and hair cortisol concentrations. Dev Psychol 2021;57:1149-62.

44. Lillberg K, Verkasalo PK, Kaprio J, Teppo L, Helenius H, Koskenvuo M. Stressful life events and risk of breast cancer in 10,808 women: a cohort study. Am J Epidemiol 2003;157:415-23.

45. Price MA, Tennant CC, Smith RC, Butow PN, Kennedy SJ, Kossoff $\mathrm{MB}$, et al. The role of psychosocial factors in the development of breast carcinoma: Part I. The cancer prone personality. Cancer 2001;91:679-85.

46. Butow PN, Hiller JE, Price MA, Thackway SV, Kricker A, Tennant CC. Epidemiological evidence for a relationship between life events, coping style, and personality factors in the development of breast cancer. J Psychosom Res 2000;49:169-81.

47. Kerr J, Anderson C, Lippman SM. Physical activity, sedentary behaviour, diet, and cancer: an update and emerging new evidence. Lancet Oncol 2017;18:e457-e71.

48. Green McDonald P, O'Connell M,LutgendorfSK. Psychoneuroimmunology and cancer: a decade of discovery, paradigm shifts, and methodological innovations. Brain Behav Immun 2013;30 Suppl:S1-9.

49. Lyon D, Elmore L, Aboalela N, Merrill-Schools J, McCain N, Starkweather A, et al. Potential epigenetic mechanism(s) associated with the persistence of psychoneurological symptoms in women receiving chemotherapy for breast cancer: a hypothesis. Biol Res Nurs 2014;16:160-74.

50. Flint MS, Baum A, Episcopo B, Knickelbein KZ, Liegey Dougall AJ, Chambers WH, et al. Chronic exposure to stress hormones promotes transformation and tumorigenicity of 3T3 mouse fibroblasts. Stress 2013;16:114-21.

51. Aboalela N, Lyon D, Elswick RK, Kelly DL, Brumelle J, Bear HD, et al. Perceived Stress Levels, Chemotherapy, Radiation Treatment and Tumor Characteristics Are Associated with a Persistent Increased Frequency of Somatic Chromosomal Instability in Women Diagnosed with Breast Cancer: A One Year Longitudinal Study. PLoS One 2015;10:e0133380.

52. Hara MR, Kovacs JJ, Whalen EJ, Rajagopal S, Strachan RT, Grant W, et al. A stress response pathway regulates DNA damage through $\beta 2$ adrenoreceptors and $\beta$-arrestin-1. Nature 2011;477:349-53.

53. Antoni MH, Lutgendorf SK, Blomberg B, Carver CS, Lechner S, Diaz A, et al. Cognitive-behavioral stress management reverses anxiety-related leukocyte transcriptional dynamics. Biol Psychiatry 2012;71:366-72.

54. Shim EJ, Lee JW, Cho J, Jung HK, Kim NH, Lee JE, et al. Association of depression and anxiety disorder with the risk of mortality in breast cancer: A National Health Insurance Service study in Korea. Breast Cancer Res Treat 2020;179:491-8.

55. Hjerl K, Andersen EW, Keiding N, Mouridsen HT, Mortensen PB, Jørgensen T. Depression as a prognostic factor for breast cancer mortality. Psychosomatics 2003;44:24-30.

56. Vodermaier A, Linden W, Rnic K, Young SN, Ng A, Ditsch N, et al. Prospective associations of depression with survival: a population-based cohort study in patients with newly diagnosed breast cancer. Breast Cancer Res Treat 2014;143:373-84.

57. Sephton SE, Dhabhar FS, Keuroghlian AS, Giese-Davis J, McEwen BS, Ionan AC, et al. Depression, cortisol, and suppressed cell-mediated immunity in metastatic breast cancer. Brain Behav Immun 2009;23:1148-55.

58. Blomberg BB, Alvarez JP, Diaz A, Romero MG, Lechner SC, Carver CS, et al. Psychosocial adaptation and cellular immunity in breast cancer patients in the weeks after surgery: An exploratory study. J Psychosom Res 2009;67:369-76.

59. Reiche EM, Nunes SO, Morimoto HK. Stress, depression, the immune system, and cancer. Lancet Oncol 2004;5:617-25.

60. Reynolds P, Kaplan GA. Social connections and risk for cancer: prospective evidence from the Alameda County Study. Behav Med 1990;16:101-10.

61. Dedert E, Lush E, Chagpar A, Dhabhar FS, Segerstrom SC, Spiegel D, et al. Stress, coping, and circadian disruption among women awaiting breast cancer surgery. Ann Behav Med 2012;44:10-20.

62. Tjemsland L, Søreide JA. Når kreftsykdommen kommer i tillegg.... Tidsskr Nor Laegeforen 2001;121:1046-51.

63. Sephton SE, Koopman C, Schaal M, Thoresen C, Spiegel D. Spiritual expression and immune status in women with metastatic breast cancer: an exploratory study. Breast J 2001;7:345-53.

64. Christie W, Moore C. The impact of humor on patients with cancer. Clin J Oncol Nurs 2005;9:211-8.

65. Kroenke CH, Kubzansky LD, Schernhammer ES, Holmes MD, Kawachi I. Social networks, social support, and survival after breast cancer diagnosis. J Clin Oncol 2006;24:1105-11.

66. Kroenke CH, Michael Y, Tindle H, Gage E, Chlebowski R, Garcia L, et al. Social networks, social support and burden in relationships, and mortality after breast cancer diagnosis. Breast Cancer Res Treat 2012;133:375-85.

67. Muthuswamy R, Okada NJ, Jenkins FJ, McGuire K, McAuliffe PF, Zeh $\mathrm{HJ}$, et al. Epinephrine promotes COX-2-dependent immune suppression in myeloid cells and cancer tissues. Brain Behav Immun 2017;62:78-86.

68. Niraula A, Wang Y, Godbout JP, Sheridan JF. Corticosterone Production during Repeated Social Defeat Causes Monocyte Mobilization from the Bone Marrow, Glucocorticoid Resistance, and Neurovascular Adhesion Molecule Expression. J Neurosci 2018;38:2328-40.

69. Quan N, Avitsur R, Stark JL, He L, Lai W, Dhabhar F, et al. Molecular mechanisms of glucocorticoid resistance in splenocytes of socially stressed male mice. J Neuroimmunol 2003;137:51-8.

70. Antoni MH, Lutgendorf SK, Cole SW, Dhabhar FS, Sephton SE, McDonald PG, et al. The influence of bio-behavioural factors on tumour 
biology: pathways and mechanisms. Nat Rev Cancer 2006;6:240-8.

71. Tillage RP, Wilson GE, Liles LC, Holmes PV, Weinshenker D. Chronic Environmental or Genetic Elevation of Galanin in Noradrenergic Neurons Confers Stress Resilience in Mice. J Neurosci 2020;40:7464-74.

72. Witek-Janusek L, Albuquerque K, Chroniak KR, Chroniak C, DurazoArvizu R, Mathews HL. Effect of mindfulness based stress reduction on immune function, quality of life and coping in women newly diagnosed with early stage breast cancer. Brain Behav Immun 2008;22:969-81.

73. Bower JE, Greendale G, Crosswell AD, Garet D, Sternlieb B, Ganz PA, et al. Yoga reduces inflammatory signaling in fatigued breast cancer survivors: a randomized controlled trial. Psychoneuroendocrinology 2014;43:20-9.

74. Blask DE, Sauer LA, Dauchy RT. Melatonin as a chronobiotic/anticancer agent: cellular, biochemical, and molecular mechanisms of action and their implications for circadian-based cancer therapy. Curr Top Med Chem 2002;2:113-32.

75. Kelly CM, Juurlink DN, Gomes T, Duong-Hua M, Pritchard KI, Austin PC, et al. Selective serotonin reuptake inhibitors and breast cancer mortality in women receiving tamoxifen: a population based cohort study. BMJ 2010;340:c693.

76. Chubak J, Bowles EJ, Yu O, Buist DS, Fujii M, Boudreau DM. Breast cancer recurrence in relation to antidepressant use. Cancer Causes Control 2016;27:125-36.

77. Shoval G, Balicer RD, Feldman B, Hoshen M, Eger G, Weizman A, et al. Adherence to antidepressant medications is associated with reduced premature mortality in patients with cancer: A nationwide cohort study. Depress Anxiety 2019;36:921-9.

78. Navari RM, Brenner MC, Wilson MN. Treatment of depressive symptoms in patients with early stage breast cancer undergoing adjuvant therapy. Breast Cancer Res Treat 2008;112:197-201.
79. Lutgendorf SK, Andersen BL. Biobehavioral approaches to cancer progression and survival: Mechanisms and interventions. Am Psychol 2015;70:186-97.

80. Stagl JM, Lechner SC, Carver CS, Bouchard LC, Gudenkauf LM, Jutagir $\mathrm{DR}$, et al. A randomized controlled trial of cognitive-behavioral stress management in breast cancer: survival and recurrence at 11-year followup. Breast Cancer Res Treat 2015;154:319-28.

81. Crielaard L, Nicolaou M, Sawyer A, Quax R, Stronks K. Understanding the impact of exposure to adverse socioeconomic conditions on chronic stress from a complexity science perspective. BMC Med 2021;19:242.

82. Dearing C, Morano R, Ptaskiewicz E, Mahbod P, Scheimann JR, Franco-Villanueva A, et al. Glucoregulation and coping behavior after chronic stress in rats: Sex differences across the lifespan. Horm Behav 2021;136:105060.

83. Lopez J, Bagot RC. Defining Valid Chronic Stress Models for Depression With Female Rodents. Biol Psychiatry 2021;90:226-35.

84. Nakash O, Levav I, Aguilar-Gaxiola S, Alonso J, Andrade LH, Angermeyer MC, et al. Comorbidity of common mental disorders with cancer and their treatment gap: findings from the World Mental Health Surveys. Psychooncology 2014;23:40-51.

85. Lin PJ, Kleckner IR, Loh KP, Inglis JE, Peppone LJ, Janelsins MC, et al. Influence of Yoga on Cancer-Related Fatigue and on Mediational Relationships Between Changes in Sleep and Cancer-Related Fatigue: A Nationwide, Multicenter Randomized Controlled Trial of Yoga in Cancer Survivors. Integr Cancer Ther 2019;18:1534735419855134.

How to cite this article: Chen X, Wang M, Yu K, Xu S, Qiu P, Lyu Z, et al. Chronic stress-induced immune dysregulation in breast cancer: Implications of psychosocial factors. J Transl Intern Med 2021; AOP. 